\title{
The Interplay of CSR (Corporate Social Responsibility) and Individual Social Responsibility (ISR) towards Enhanced Organizational Resilience in MNCs
}

\author{
Zahra GorjianKhanad1, Ali A. Gooyabadi² \\ ${ }^{1}$ California Miramar University, San Diego, CA, USA \\ ${ }^{2}$ Adcademic Department, DeVry University, San Diego, CA, USA \\ Email: zgorjian@calmu.edu, agooyabadi@devry.edu
}

How to cite this paper: GorjianKhanad, Z., \& Gooyabadi, A. A. (2022). The Interplay of CSR (Corporate Social Responsibility) and Individual Social Responsibility (ISR) towards Enhanced Organizational Resilience in MNCs. Open Journal of Business and Management, 10, 314-336.

https://doi.org/10.4236/ojbm.2022.101019

Received: December 7, 2021

Accepted: January 16, 2022

Published: January 19, 2022

Copyright $\odot 2022$ by author(s) and Scientific Research Publishing Inc. This work is licensed under the Creative Commons Attribution International License (CC BY 4.0).

http://creativecommons.org/licenses/by/4.0/

\section{Open Access}

\begin{abstract}
Individual Social Responsibility (ISR) is becoming a fundamental pillar for companies with transparent Corporate Social Responsibility (CSR) strategies. This approach leverages the inseparability of an individual's cultural and socioeconomic from contextual factors such as environmental, social, economic, and stakeholder perspectives. This paper will focus on the enhancement of organizational resilience through positive interaction between ISR and CSR. CSR is the result of evolutionary practices responding to the fulfillment of society's demand for more ethical, transparent, and trustworthy organizations. However, research indicates that CSR cannot be effective without adherence to the ISR principles aligned with the demanded premises and values.
\end{abstract}

\section{Keywords}

CSR (Corporate Social Responsibility), Individual/Personal Social Responsibility (I/PSR), Organizational Resilience, Corporate/Individual Culture

\section{Introduction}

The phenomenon of Corporate Social Responsibility (CSR) has increasingly grown during the last few decades and has been considered one of the powerful catalyst concepts for sustainability (Idowu \& Filho, 2009). Considering signifi- 
cant paradigm-shifting movement towards CSR contributions, MNCs confront global pressure to modify their corporate strategy and promote their CSR programs. The other aspect of social responsibility is Individual Social Responsibility that represents the individual's voluntary actions towards others' well-being based on his/her perception to improve community and society (Mihaela, 2018). Different studies reveal that individuals engage in socially responsible exercises to satisfy their self-esteem need at a personal level (Shanti \& Saloni, 2016: pp. 36-44). Bartel's empirical study (2001) exhibited that any positive type of engagement in socially responsible practices boosts morale in the society and enhances collective self-esteem as well as the power of identity within the organization and society.

For individuals working as employees in organizations, effective engagement in CSR exercises satisfies their needs for security, belongingness, and participation in a meaningful existence (Baumana \& Skitka, 2012: pp. 63-86). It seems significant, logical, and beneficial that Social Responsibility should be evaluated simultaneously from corporate and individual perspectives to discover potential synergistic aspects. This paper strives to contribute by enhancing sustainable development that encompasses social responsibility by discovering and formalizing the interplay between ISR and CSR. This study portrays that existing literature on the interplay of ISR and CSR at best is scant; therefore, the existing publications represent a black box that this research aims to formalize.

Corporations usually consider themselves as active players in the process of sustainable development that encompasses social responsibility. Large enterprises such as multinational corporations (MNCs) contain many diverse and sometimes conflicting cultures. With the advent of globalization, it has become essential for MNCs to consider the concept of multiculturism when deciding on their organizational strategy towards CSR. The research employs the Triple Bottom Line (TBL) and its elevated application to multinational corporations in satisfying the social and environmental requirements as one of the principles in developing a conceptual framework through a deductive approach. The existing literature paves the way for developing the proposed conceptual framework towards enhanced organizational resilience by implementing Pattern Matching. Result suggests that a shared, unified, transnational culture can be the best motivator for all stakeholders operating in MNCs to assimilate separate cultures and social expectations and increase the resilience built on multiculturalism. The present study's finding shows that well-orchestrated CSR and ISR coordination is the resilient recipe for any MNCs in the turbulent market.

The following section illustrates a condensed presentation of selected literature followed by a material and methods section. This section reviews the five main theoretical frameworks that set the foundation of this research. The development of the proposed framework is presented in Section 4, followed by a discussion in Section 5. 


\section{Literature Review}

In recent years, the concept of CSR has earned special attention due to the increased awareness in the business environment. With the advent of globalization, CSR has become more international (Andersson, 2006), where large corporations and multinational corporations (MNCs) need to contribute more to global sustainability (Woo \& Jin, 2015: pp. 37-55). Due to the different inherent expectations from the diverse cultural lenses, it is pivotal for Multinational corporations (MNCs) to consider the effect of different cultures in their strategic approaches in undertaking CSR. Investigating more in-depth into the prevalence of the new CSR movement across the Golab reveals the significance and pertinency of Individual Social Responsibility (ISR) that can be viewed from different perspectives.

Corporate social responsibility (CSR) has extended into a global trend by massive media coverage (Sahlin-Andersson, 2006). Even though there is not a universally accepted definition for CSR, the World Business Council for Sustainable Development defines CSR as an abiding commitment by businesses to contribute to economic development and behave ethically while improving the quality of life of the workforce, the local community, and society at large besides their families (World Business Council for Sustainable Development, n.d.). CSR's concept applies to all organizations independent of their size; however, CSR's primary focus tends to be on larger businesses as these corporations have more power and influence in furthering society's sustainability (Carroll, 2008: pp. 1-13).

Due to this globalization, the business environment today is more international than ever; and as such, the concept of cross-cultural adaptation has become profoundly crucial for businesses and individuals operating abroad (Williams, 2008). When entering international markets, the analysis of dominant global players indicates two management strategies, such as adaptation and standardization (Ryans et al., 2003: pp. 588-603). The term "glocalization" was coined by Matusitz (2011: pp. 418-429) to express the importance of cross-cultural adaptation for multinational corporations (MNCs) by the two-pronged approach of "globalization" and "localization" in adapting their business practices to satisfy the local preferences appropriately (Matusitz, 2011: pp. 418-429). According to Filatotchev and Stahl's (2015) framework, Multinational corporations (MNCs) require to consider both local and global expectations and stockholders' interests simultaneously to formulate and develop the most appropriate strategies. However, balancing local and global requirements aligned with "global consistency in CSR approaches" is exceptionally challenging (Dahlsrud, 2008).

Porter and Kramer (2006) believe that CSR has become a priority for businesses in such a way that it has become a great source of a competitive advantage that cannot be avoided or ignored (Slack et al., 2015: pp. 537-548). Multinational corporations (MNSc) need to recognize international market cultures from do- 
mestic CSR standards perspectives to determine how exactly CSR practices are adapted to the firm's country of origin (Woo \& Jin, 2015: pp. 37-55) since various cultures have different expectations of companies' responsibilities towards society (Burton et al., 2000: pp. 151-167). In today's global market, MNCs are confronting increasingly complicated and even competing social expectations (Arthaud-Day, 2005) in the host countries compared to the country of origin's expectations (Muller, 2006: pp. 189-198). In these circumstances, MNCs tend to interpret CSR policies that are often associated with their national "administrative heritage" that ultimately might create conflicts in confrontation with different cultures in the host countries (Arthaud-Day, 2005).

Recent studies have increasingly concentrated on consumer behavior and new ethical consumption tendencies, which have been decomposed to different perspectives such as ethical and social behavior, sustainability, personal and conscious responsibility (Vitell, 2015: pp. 767-774). In this context, the consumers' category is one division of individuals, and behavior has overstepped the limits of a minor economic exchange and consumption. Anderson and Cunningham (1972) defined ISR as "The enthusiasm of an individual to help others even when there is no economic gain for himself”. According to Melé, the market system consists of individuals, and as such, if all individuals change their way of thinking, being, operating, the ultimate form of the economic model will change (Melé, 2009).

This new wave of change has been rising during the last decades, where consumers realized their economic power in their purchase decisions to control and impact the way corporations behave (López et al., 2017). The significant influence and power of consumer decisions on the organizational management that will shape societies' evolution are the main contributions of individual responsibility through green or ethical behavior (Ha-Brookshire \& Hodges, 2009; Mohr et al., 2001: pp. 45-72; Vitell, 2015: pp. 767-774). Therefore, this paper addresses the interplay of ISR and CSR towards enhanced organizational resilience.

The conception of Individual social responsibility (ISR) should be aligned with the CSR patterns to facilitate organizational resilience. Considering that CSR describes the relationship between businesses and society as a whole (Snider et al., 2003: pp. 175-187), ISR/PSR should represent the personal behavior and individual contributions through daily decisions and the consequential effect of individuals' behavior on the social and ecological environment (López et al., 2017). Studies show that individuals who are more sensitive to corporate social performance hold values aligned with ISR principles attempting to bring resilience to the corporation through multi-fiduciary management (Giacalone et al., 2005: pp. 295-305). Rest's (1986) individual ethical decision-making theory introduced a different model about individual ethical behavior that can be generalized to organizational settings. Some scholars have argued that CSR's concept and its effect on society are basically the extents to which it encompasses almost every individual's role, like a consumer, employee, or interested or uninterested 
observer (López Davis, 2017).

Resilience is one of the most crucial aspects of organizational life. The reality is, "today's world is becoming turbulent faster than organizations are becoming resilient" (Hamel \& Välikangas, 2003: pp. 52-63). In the dynamic global market, organizations are under constant pressure, but the individuals' approach towards the organization can make or break the business. The prevailing culture, dominant behavioral pattern, and leaders' capabilities can enhance or erode organizational and individual resilience (Seville, 2018). Resilient organizations succeed despite enduring conditions that are uncertain and usually unstable. Lengnick-Hall et al. (2011) believe that building resilience is possible only through strategically managing human resources within a corporation to create competencies among employees. Therefore, under aggressive circumstances, organizations are able to respond in a resilient manner when individuals have resilience.

\section{Materials and Methods}

This paper proposes a conceptual framework through a qualitative analysis of existing academic resources regarding successful CSR undertaking in multinational corporations (MNCs) by leveraging ISR. Considering the exploratory nature of the current research undertaking, existing empirical research literature pertinent to the topic of this research is investigated towards the formulation of a suitable CSR implementation conceptual framework for multinational corporations (MNCs).

Exploratory research can be classified into two main methods: the primary research method and the secondary research method. Due to the inherent nature of the topic, the Secondary research method is used in this paper. Existing sources, like Literature researches and scholarly articles, are gathered and investigated. The literature review procedure included a semi-systematic search of available resources and relevancy analysis. Literature collection involved the selection from the various electronic resources. The academic journals were screened for articles including "corporate social responsibility, individual/personal social responsibility, organizational resilience, corporate/individual culture, triple bottom line, sustainability" in "title, keywords, or abstract." Moreover, the research was conducted considering the following set of criteria:

- Only full-text English articles from major journals, including:

- Journal of Business and Society

- Business Ethics

- Journal of Marketing

- Economica

- Journal of Management studies

- Strategic Management Journal

- Sustainability Journal

- Book chapters, or e-books (including a few conference proceedings and 
working papers)

- Except for the foundational/theoretical material, all applied publication time frame covers the period from 2001 to the present, both inclusive, as the most recent studies on the topic are the ones that were the significance of the proposed framework development.

The literature analysis comprises several steps. First, all relevant articles were tagged and stored. In this phase, duplications were identified. After reviewing a total of 187 abstracts, 77 relevant articles were selected. The study of existing literature clearly demonstrates that the interplay of CSR and ISR under the influence of culture towards creating a resilient organization has never been studied. As such, the proposed conceptual framework for the interaction of CSR and ISR towards enhanced organizational resilience is an attempt to answer such a profound inquiry.

Five main theoretical frameworks are selected amongst all existing researches. One of them is the theoretical framework proposed by Lv et al. (2019), in which they analyzed the effect of different aspects of CSR on a corporate's long-term growth and financial volatility. Lv et al. categorized CSR's roles in resilience into CSR's performance-enhancing and performance-insuring mechanisms ( $\mathrm{Lv}$ et al., 2019). The second model is the Kaz (2019) Trigon consultancy model that addresses the connection between four main aspects of self, team, organization, and environment in building resilient culture, trusty corporate culture, and a high-level CSR policy. The third conceptual model proposed by Edwards and Phan (2014) and Athanasopoulou and Selsky (2015) on CSR's nature. The fourth model developed by Husain Ebrahim \& Buheji (2020) presents a holistic Framework of CSR and ISR strategies towards migrating chaos. The last conceptual model is called the triple bottom line (TBL), demonstrated by UNIDO (2017) that balances three concepts of social performance, environmental performance, and economic performance. This paper's conceptual model has borrowed different fundamental concepts from five of those mentioned above conceptual and theoretical frameworks and has added culture's inevitable effect in organizational resilience enhancement through the causal interplay of Corporate Social Responsibility (CSR) and Individual Social Responsibility (ISR).

In most countries worldwide, CSR plays a more critical role in business practices since there is a developing demand for sustainability. Many companies being small, medium, or multinational corporates, follow CSR principles, either compulsory or voluntary. CSR empowers organizations to practice transparency, accountability, and responsibility (Gjølberg, 2009; Kleinrichert, 2007) to their society and environment and enables businesses to stay sustainable and profitable while they are operating ethically. Also, Porter and Kramer (2006: pp. 78-92) claimed that businesses have the ability to generate economic value by producing societal value. They assumed that companies could increase value by adhering to a virtuous circle of shared value if they could orchestrate their resources to deliver better products innovatively with less damage to the environment (Porter 
\& Kramer, 2006: pp. 78-92). Many scholars have tried to present a universal definition of CSR; however, many different definitions are trying to address various aspects of CSR. Piboolsravut defined CSR as "the process of fulfilling society's requirements through the continuous improvement of organizational performances by considering all stakeholders' needs to develop a competitive advantage that will guarantee the long-lasting sustainability of both corporate and society" (Piboolsravut, 2004: pp. 127-134). With the advent of globalization and the growth of multinational companies (MNCs) operating worldwide, Zadek (2001) believes that CSR contributes to global problems such as poverty, pollution, and human rights violations and has stirred the demand for business involvement for social betterment.

The intentions behind defining and implementing CSR in different organizations have been controversial. Internal and external forces can be the initiator cause of CSR. CSR's overall purpose is a convergence of social conscience and business strategy for balanced well-being and benefit. But CSR can be defined as an extensive range of programs or practices with different intentions, motivations, policies, guiding principles, and diverse backgrounds of company relationships within society (Baughn et al., 2007).

The theoretical framework proposed by Lv et al. (2019) identified organizational resilience's conceptualization and operationalization. Corporates are dynamic, and therefore, they are in constant interaction with the market environment, and the way corporate responses to the market volatility will determine the organization's future. However, some aspects like organizational resilience are not easy to measure since there is no definite and non-abstract Key Performance Index (KPIs) for evaluating such a latent, unobservable construct (Ortiz-de-Mandojana \& Bansal, 2016). In today's turbulent business market, resilient organizations are required to identify the possible opportunities and envision imminent threats to utilize their power and restrain the negative impacts. Accordingly, large and multinational corporations need to maintain the preferred performance during the upheaval and stay consistent with the mainstream view (Ortiz-de-Mandojana \& Bansal, 2016; Markman \& Venzin, 2014).

Lv et al. (2019) analyzed CSR's effect on corporates' constant growth and financial volatility through corporate social responsibility performance-enhancing and performance-insuring mechanisms. They argued that through the performance-enhancing mechanism, the corporate social responsibility (CSR) could improve performance growth by increasing employee satisfaction and employee retention (Bode et al., 2015), innovation, and creativity (Abdelmotaleb et al., 2018; Bocquet et al., 2017: pp. 241-254), corporate reputation in society (Barakat et al., 2016: pp. 2325-2339), trustworthy environment (Zou et al., 2016: pp. 3765-3771), and customer satisfaction (Singh, 2016: pp. 311-326; Zou et al., 2016: pp. 3765-3771). A corporate's CSR commitment can internally increase employee satisfaction and loyalty that ultimately can lead to employees' innovative behaviors (Williams, 2008). On the other hand, the performance-insuring 
mechanism holds a proactive approach and looks at corporate social responsibility (CSR) as a crisis mitigator and filter away the possible threats and financial volatility (Shiu \& Yang, 2017: pp. 455-470). Corporate social responsibility (CSR) has been identified as one of the main enablers of organizational resilience, and as such, many scholars believe that Corporate social responsibility (CSR) plays a significant role since CSR contributes a profound social foundation for buffering disruptions (Pal et al., 2014). The performance-enhancing mechanism is aimed to raise the social concern about corporate social responsibility in developing markets. Therefore, business owners and executives should engage in CSR practices that facilitate social welfare to establish a corporate reputation and, eventually, organizational growth in the future.

The stakeholder theory demonstrates that any Corporate Social Responsibility participation requires supports (Freeman, 1984) from internal stakeholders (Freeman et al., 2010) and significant stakeholders (Eesley \& Lenox, 2005). Applying and implementing CSR offers numerous benefits to many stakeholders, such as society or community, environment, employees, and the local and global economic market. If companies commit to CSR as a long-term organizational strategy, they can empower all stakeholders to improve the sustainability needed in their business as well as the industry. They can also generate value for all stakeholders, including human resources within the company, by looking at human resources strategically and investing in human resources as valuable capital. This approach benefits all stakeholders by comprising corporate citizenship, sustainable development, advancing the competitive advantages, decreasing the risks and associated costs, brand building, and in one word implementing a win-win strategy. O'Riordan and Fairbrass's proposed framework is composed of a set of steps in developing CSR strategies, which improves the business's accountability. This framework integrates the involved stakeholder's responsibilities into possible business choices to enhance stakeholder engagement and practice CSR by companies (O'Riordan \& Fairbrass, 2014: pp. 121-145). The best possible option is to align the organization's vision and the involved stakeholders to collaboratively develop their CSR, creating further sustainable synergic and profit.

In recent studies, resilience has shifted from the ability to recovery from turmoil circumstances towards building capacity to long-lasting growth by constant self-renewal by all members of a society and in all levels from individuals to organizations and other social systems (Gao et al., 2017; Pal et al., 2014). Kaz (2019) defined organizational resilience as an organization's ability to foresee, get ready, respond, and adjust to incremental change and unexpected disruptions to be able to survive and succeed. He also argues that SME companies have recently started to realize that successful businesses are built upon a resilient culture, structures, and productive environment embedded in a high-level CSR policy. Proper corporate governance ensures organizational resilience through the demonstration of flexibility, robustness, and cleverness at the same time. So, a resilient company should embrace the capability of creating a balance between 
efficiency and resilience. Välikangas's empirical study revealed the five dimensions of organizational resilience, which are adaption, culture, design, organizational intelligence, and resourcing (Välikangas \& Romme, 2013). CSR will become a natural part of the organization that does not need any external intervention in such an organization. It seems that corporate governance and organizational resilience are the basis for all-embracing CSR.

Due to the increasingly turbulent market environment, businesses must develop their organizational resilience by building the ability to successfully deal with the detrimental effect of environmental changes on their survival and growth (Timothy et al., 2010). In this context, organizational resilience should offer various insights on corporate requirements for furthering stability through a strategic cultural approach. The socio-political ecosystem is enforcing a paradigm shift to building organizational resilience in achieving a suitable CSR through proper corporate governance. Organizational resilience is a strategic approach that integrates many different facets of the organization into a coherent regiment toward increased sustainability (Lengnick-Hall et al., 2011). Therefore, building organizational resilience has played a crucial part in the public persona during the last decades. Corporate Social Responsibility (CSR) and organizational resilience go hand in hand as corporations' contributions continue to grow. Society-related CSR is another factor addressed in Lv et al.'s theoretical framework. Companies participate in society-related CSR when they donate to charity and non-profit organizations. The primary purpose is to achieve a social reputation that aims to major targets naming, create value for the organization (Orlitzky et al., 2003: pp. 403-441), bring long-term benefits (Gautier \& Pache, 2013), and reduce economic volatility imposed by the market. The socially-related CSR plays a significant role in multinational corporations since creating a solid social reputation is profoundly essential to their success.

The evolving business environment creates opportunities and challenges such as economic recessions, new technologies, innovative non-traditional competitors, and regulatory upheavals for all active organizations and draws business owners' attention to organizational resilience (Hamel \& Välikangas, 2003: pp. 52-63). Organizational resilience requires significant undertakings such as redesigning organizational structure in line with a resilient value system, reallocating financial resources, empowering human capital, redefining corporate culture, and sustainable stakeholder interactions. Companies require to positively engage in CSR exercises to build an appropriate relationship with stakeholders to get the essential resources and required support to achieve their organizational resilience successfully.

Figure 1 demonstrates Lv et al.'s theoretical framework that shows the effect of performance-enhancing and performance-insuring mechanisms of CSR engagement in organizational resilience.

Kaz's study debates that more companies have recently become conscious that their businesses' success is in lieu of a resilient culture and proper structures, 


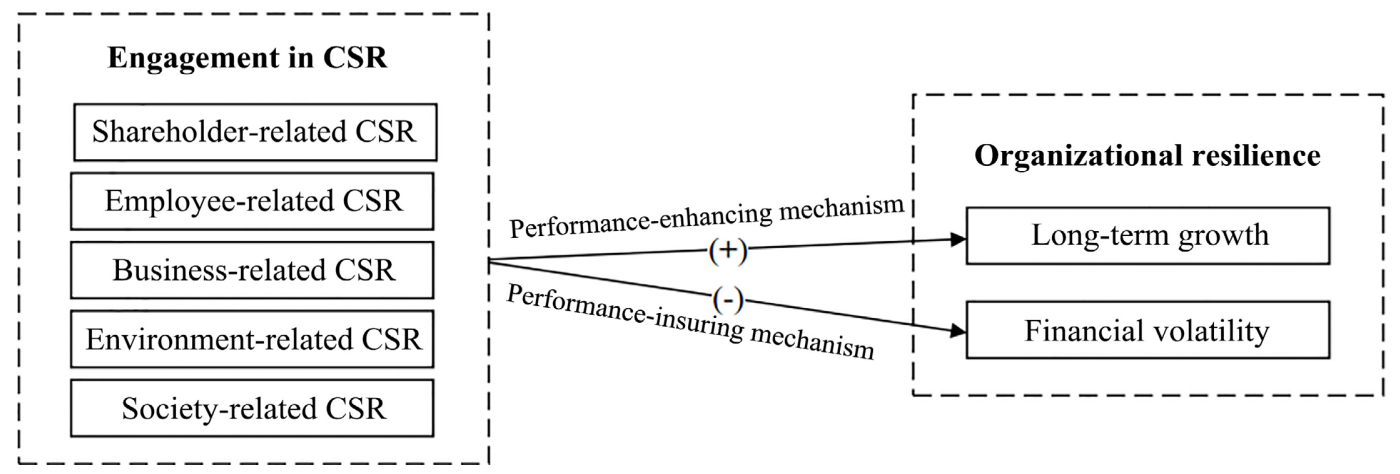

Figure 1. Lv et al.'s theoretical framework. Source: Lv et al. (2019). What Dimension of CSR Matters to Organizational Resilience? Evidence from China. Sustainability. Copyright 2019 by CCAL.

creating a healthy, trustworthy corporate with a high-level CSR policy (Kaz, 2019). Kaz (2019) represented the Trigon consultancy model (Kaz, 2019) consisting of four dimensions relevant to organizational resilience (Figure 2). They defined the Self aspect as the way that individuals try to create meaning in life and bring balance to their world by increasing awareness about society and the world. This dimension addresses ISR, demonstrating the ability to positively contribute to the world to increase happiness in personal life, and promote organizational resilience professionally. A trustful corporate culture in any team that is dialogue-oriented promotes diversity and encourages innovative decisions. In this team, members live in a learning organization that, by concentrating on innovation, welcomes a "culture of error" and eliminates possible blockades and risks. Therefore, the organization has foreseen the market volatility and risks and looks for novel and innovative solutions by thinking the unthinkable (Kaz, 2019).

Edwards and Phan (2014) and Athanasopoulou and Selsky (2015) proposed a conceptual framework on the nature of CSR (Figure 3). This conceptual model shows that organizations reside in nested arrangements and, as such, the organizational behaviors and cultural patterns come from contextual influences originating from diverse levels of social context (Rowley \& Moldoveanu, 2003: pp. 204-219). Athanasopoulou and Selsky (2015) added three layers of circles, namely the individual level, organizational context, and external social context enveloping the core component (CSR). The individual-level represents the individual mind setting embedded in ethical and core values or beliefs that shape individuals' behavioral patterns and decisions (Bartel, 2001). The individual-level expands to a larger scale, such as organizations and society, and how every individual behaves as a responsible and moral human being (Rest, 1986).

Therefore, it is essential to pay particular attention to the significance of individuals in shaping CSR (Filatotchev \& Stahl, 2015: pp. 121-129) and stakeholders who are key individuals like business owners and managers in an organization since they are key players who take an active role in the initiation and development of CSR practices in corporations (Muller, 2006: pp. 189-198). Also, the role 


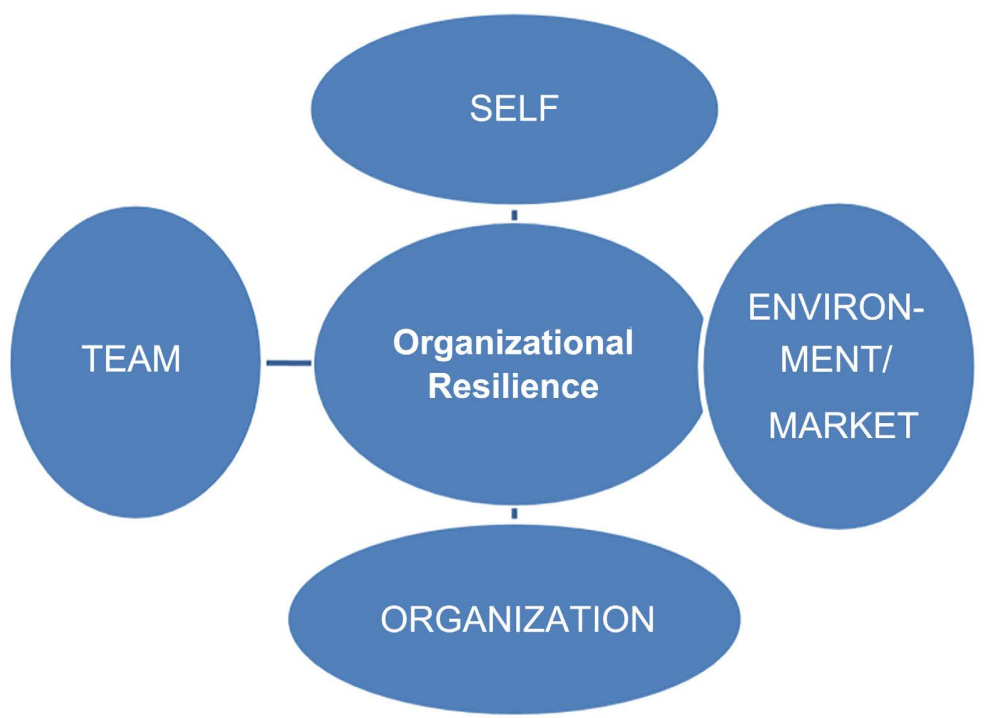

Figure 2. Trigon consultancy model. Source: Kaz, (2019). Building Resilience into the Organization. International Dimensions of Sustainable Management. Copyright 2019 by Springer.

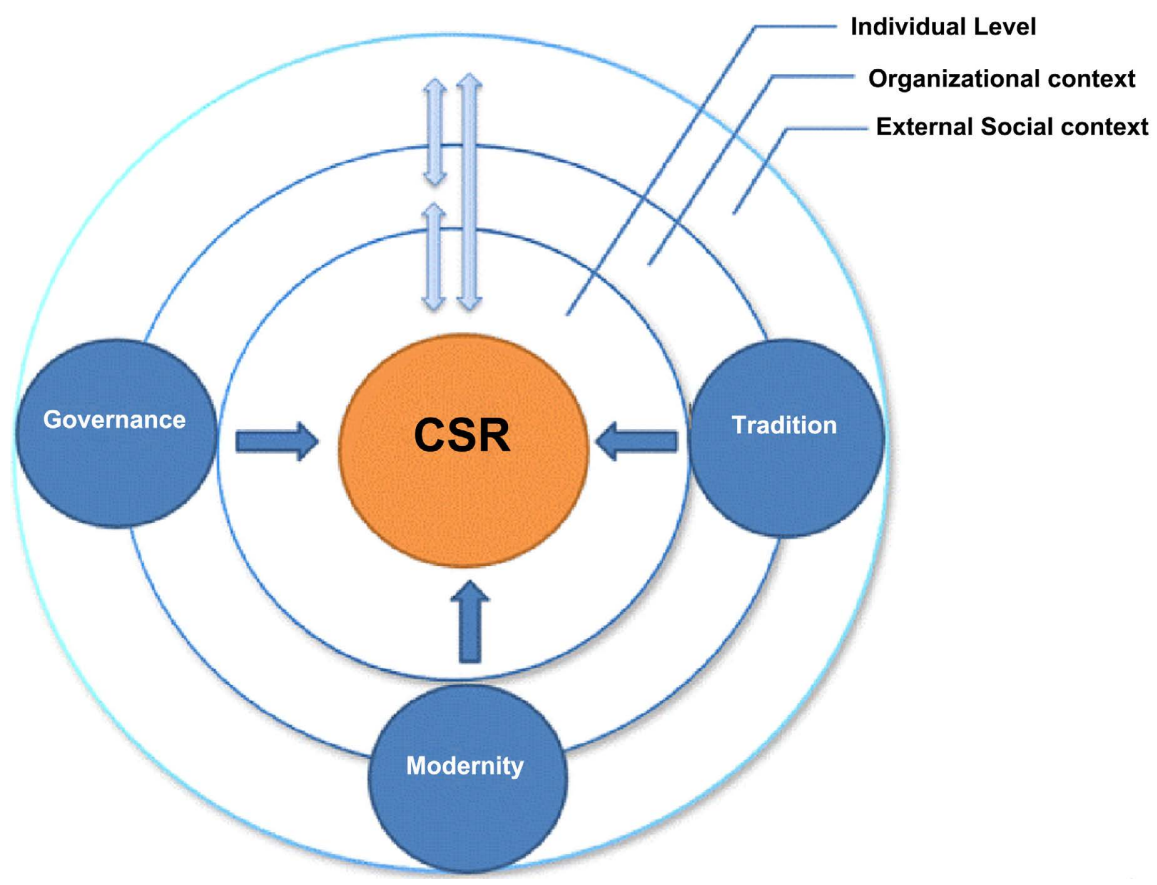

Figure 3. CSR and organization conceptual framework. Source: adapted from Edwards and Phan (2014), Managers and management in Vietnam: 25 years of economic renovation, Oxford: Routledge and Athanasopoulou and Selsky (2015). The social context of corporate social responsibility: Enriching research with multiple perspectives and multiple levels. Business \& Society. Copyright 2014 by Routledge.

of Individual Social Responsibility towards organizational resilience should not be ignored.

The second level of this conceptual framework is the organizational context in 
which an organization communicates and negotiates with all stakeholders to proactively develop its CSR strategies (Bãnabou \& Tirole, 2010). This level incorporates the significance of organizational structure and governance as well as the corporate culture in implementing CSR commitments, especially for multinational corporations (MNCs).

The Holistic Framework of CSR and ISR strategies for Mitigation risks (Figure 4) developed by Husain Ebrahim \& Buheji (2020) exhibits the relationship between CSR and ISR. Individual social responsibility is a primary aspect that could be manifested through effective behavior to help confront the societies' challenges. If an individual's social responsibility aligns with the organizational social obligations and commitments, it creates a synergic environment leading to organizational resilience. This holistic framework combines the cultural values, personal behaviors, and socioeconomic requirements during any chaotic circumstances like the COVID-19 pandemic. According to Husain Ebrahim \& Buheji (2020), this framework is flexible, and as such, can be applied to any corporations in different industries and for different situations, regardless of the available resources. This framework's importance is to encourage initiatives and promote a unified culture built on collaboration and solidarity through positive behaviors in different levels being individual or organizational aspects.

This holistic framework exhibits that through an appropriate CSR/ISR management, any corporate or even government can develop a comprehensive plan to engage all the stakeholders to mitigate the risks and uncertainty and increase personal, organizational, and national resilience.

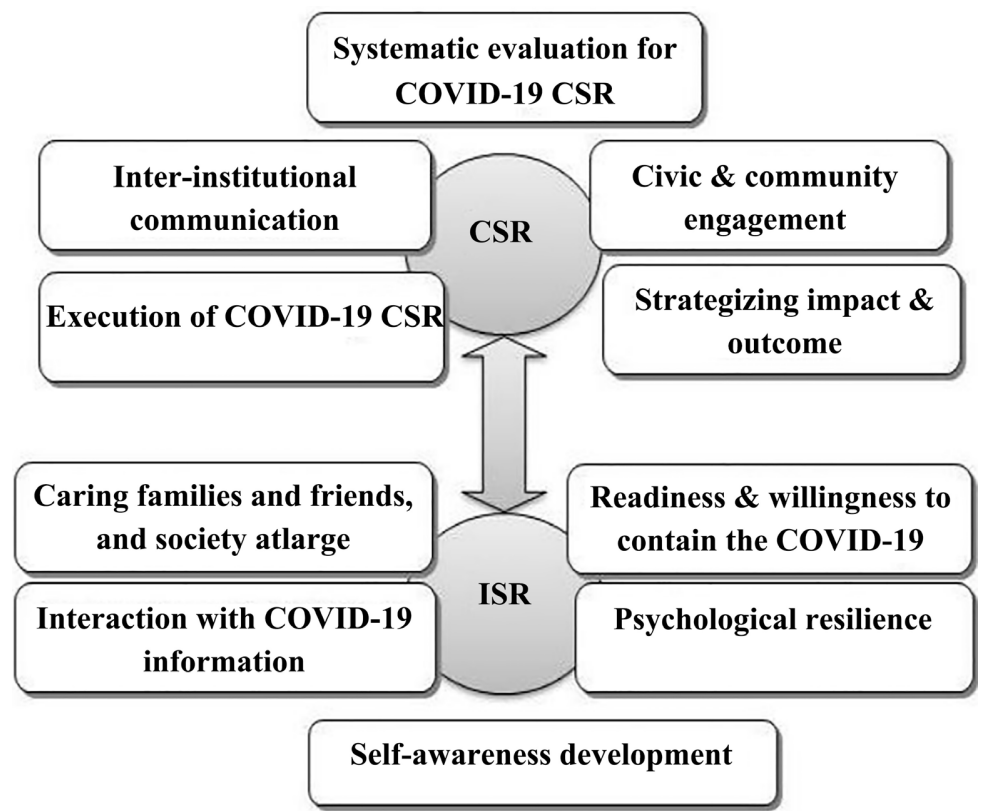

Figure 4. The holistic framework of CSR and ISR strategies for mitigation risks. Source: Husain Ebrahim, A., \& Buheji, M. (2020). A Pursuit for a "Holistic Social Responsibility Strategic Framework" Addressing COVID-19 Pandemic Needs. American Journal of Economics. Copyright 2020 by AJF. 
In the Triple-Bottom-Line (TBL) Approach model proposed by UNIDO (2017), CSR is the way for companies to attain a balance of economic, environmental, and social requirements and simultaneously address the expectations of organization shareholders and stakeholders. Therefore, CSR can be regarded as a strategic business management concept for a corporation or/and charity or philanthropy approach towards social responsibility in poverty reduction. United Nations Industrial Development Organizations also based its CSR practices on this approach. According to UNIDO (UNIDO, 2017), the Triple Bottom Line (TBL) approach is one of the most successful tools for SMEs, especially for multinational corporations (MNCs) operating in developing countries, to satisfy social and environmental requirements without compromising their competitiveness (Figure 5).

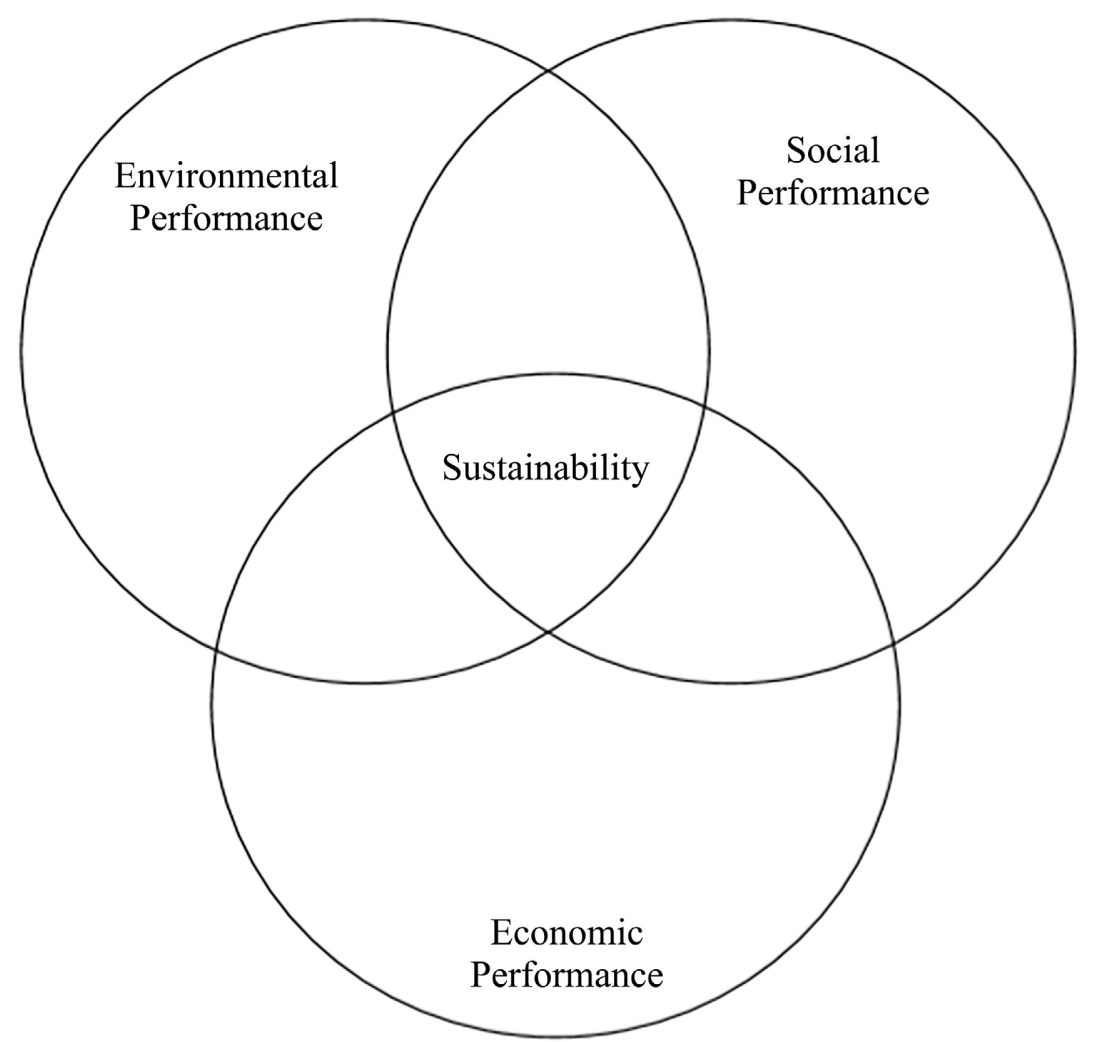

Figure 5. Triple bottom-line (TBL) approach. Source: UNIDO. (2017). What is TBL and CSR? www.Unido.Org.

A properly implemented Corporate Social Responsibility principles advance many competitive advantages, such as access to capital and markets, satisfied and motivated human resources, healthy corporate culture, a trustworthy work environment, increased brand reputation, and an integrated approach towards organization resilience.

\section{Results}

In recent years, the phenomenon of corporate social responsibility (CSR) expanded 
globally. Such increased awareness about CSR and businesses' social expectations has become more international, where multinational corporations (MNCs) encompass many diverse national cultures. With the advent of globalization, it has become essential for MNCs to take the concept of multiculturism into consideration when deciding on their organizational strategy towards CSR. Sustainable corporations have implemented sustainability initiatives in line with their corporate strategies through a shared, common corporate culture and mindsets (Savitz \& Weber, 2006). As different cultures have diverse expectations of corporations based on various perceptions, MNCs must establish a unified transnational corporate culture. Considering the national cultural differences and the fact that these differences influence the way people behave in organizations, MNCs have to take an adaptation, standardization, or glocalization strategy towards CSR concepts (Carter \& Rogers, 2008). Many corporations worldwide have incorporated CSR and, most importantly, ISR programs and practices into their Human Resource activities, so an employee's contribution towards any altruistic activity and charity is considered for his/her annual performance appraisal (Business News Live, Share Market News, IPO, Mutual Funds News, n.d.). Therefore, through the ISR advocacy corporate strategy, ISR will be treated as an added value or extra achievement for employees to inspire employees.

The sustainability concept considers various concerns about environmental and economic issues; as such, CSR conceptualizations and operationalizations address social and environmental problems. The Triple Bottom-line Approach (TBL) proposes that considering the three major elements of SEE meaning, Social performance, Environment performance, and Economic Performance, organizations can engage in practices and programs that positively affect the environment and also produce a competitive advantage for the corporation. Congruency between the three main parts of the Triple Bottom Line (TBL) approach creates sustainability, including risk management, strategy, and cultural concepts (Ha-Brookshire \& Hodges, 2009; Savitz \& Weber, 2006).

In this paper's conceptual model, the primary model has borrowed from the TBL approach (Figure 6); however, this conceptual framework adds the interplay of CSR and ISR at the intersection of Social, Economic, and Environment performances which can be an enabler to organizational resilience. According to Carter \& Rogers (2008), sustainability initiatives should align with corporate strategy and should be manifested in its strategic objectives. The Conceptual Framework for the interaction of CSR and ISR towards enhanced organizational resilience suggests that a shared, unified, transnational culture can be the best motivator for all stakeholders operating in MNCs (Antal \& Sobczak, 2007) to assimilate separate cultures and social expectations and increase the resilience built on multiculturalism. The ISR-centric organizational culture in the proposed model describes the type of culture that is deeply ingrained within a multinational organization and its people. In this organization, every individual is a citizen of an organization and, as such, performs voluntary commitment within a 


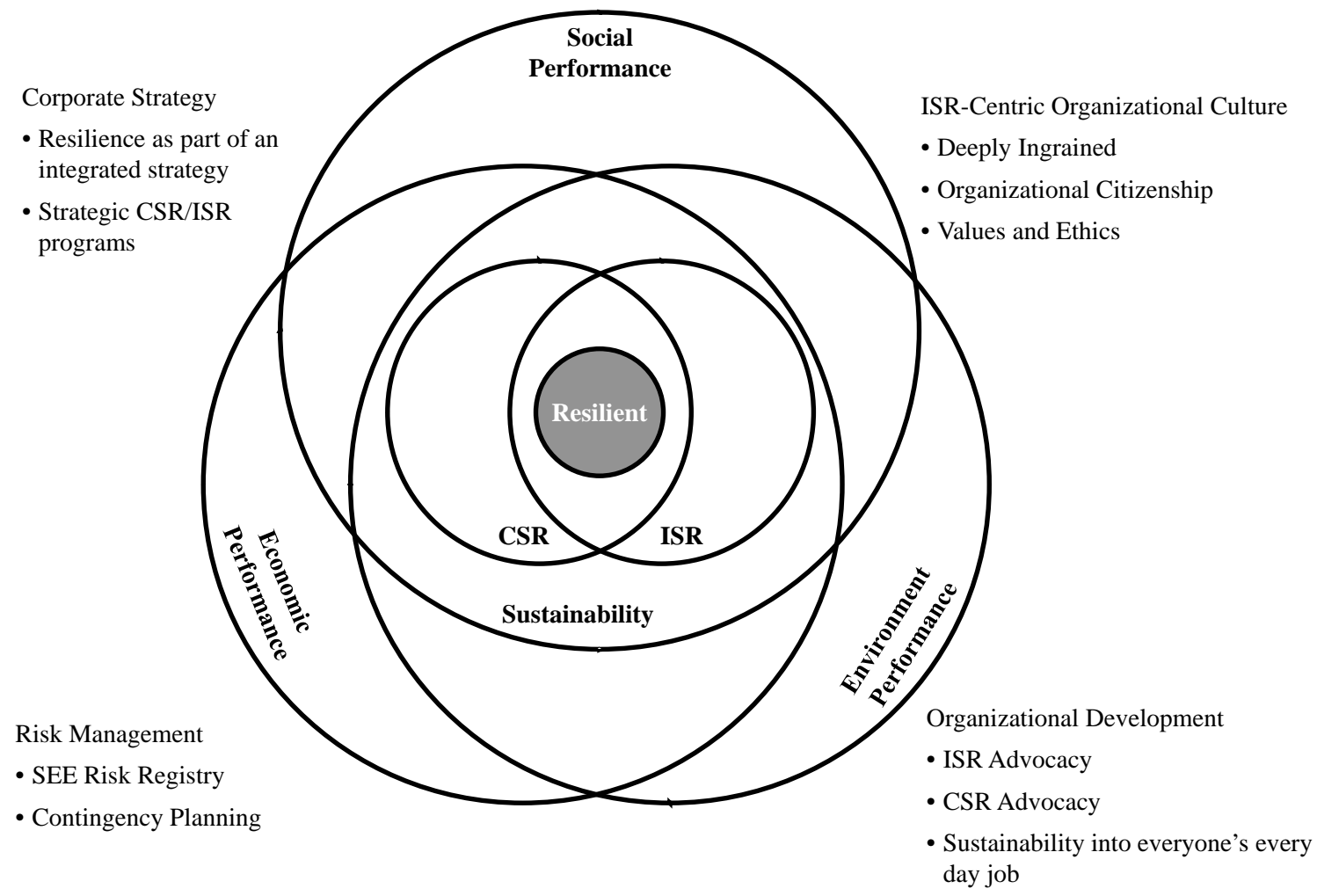

Figure 6. Proposed conceptual framework for interaction of CSR and ISR towards enhanced organizational resilience.

corporation beyond their call of organizational duty. Such an organization develops well-defined moral codes for its values, and ethical principles since value and ethics are essential to the health of the workforce and organizational communications.

Risk management of the Conceptual Framework for CSR and ISR's interaction towards enhanced organizational resilience includes all the possible risks regarding the TBL and CSR and ISR interactions. Risk management has been defined differently based on the organization's inherent nature; however, risk management can be referred to as management of issues related to swiftly and efficiently retrieving the possible damages (Corbett \& Klassen, 2006: pp. 5-22). Risk management plays a significant role in organizational resilience. Resilience presents a philosophical and methodological basis to systemic risk analysis more efficiently than risk management in traditional approaches (Hynes, 2019).

For instance, even though, according to many studies, stakeholders respond positively to CSR, which ultimately leads to a positive outcome such as financial growth or brand reputation (Rowley \& Moldoveanu, 2003: pp. 204-219; Vasi \& King, 2012: pp. 573-596), but some possible hostile and aggressive behaviors can be done by stakeholders (Doh \& Guay, 2006; Eesley \& Lenox, 2005) which can increase operational costs, public relations costs and extra-legal fees (Bendoraitiené \& Darškuviené, 2019). This Conceptual Framework suggests developing a well-designed Social, 
Economic, Environment Risk Registry to foresee and identify all possible internal and external risks and create a contingency plan to define required actions if any risks occur.

CSR and ISR strategies towards organizational resilience usually begin with the evaluation and understanding of the nature of the corporations, their circumstances in the business market, and the demands of the industry (Yin, 2018). O'Riordan and Fairbrass's framework (2014) demonstrates fundamental steps in developing CSR strategies embracing the concept of CSR strategies as a direction to generate profit by mechanisms that integrate virtuous values for sustainability through cooperation with the network of stakeholders in innovating new beneficial methods (Yin, 2018). According to O'Riordan and Fairbrass's framework (2014), Organizations need to go through four functions of resilience, including preparation and planning, absorption, recovery, and adaptation successfully and efficiently to create a resilient environment. Establishing sustainability within a corporation is considered as one of the main building blocks of the corporate strategy, especially when it comes to MNCs. It is notably challenging for MNCs to operationalize sustainability, where they are operating in different geographical locations with various prerequisites and requirements. It goes without saying that there is a considerable lag between developed and developing countries regarding the embodiment of sustainability into corporate strategy (Nasrullah \& Rahim, 2014), and as such, designing and implementing the best possible corporate strategy is profoundly critical.

Some organizations connect their performance measurement systems to corporate strategy and their vision, mission, and business objectives (Kaplan \& Norton, 2005; Neely et al., 1995: pp. 80-116). To obtain sustainability performance efficiency, the Sustainability Committee evaluates all opportunities and risks associated with the existing projects to manage stakeholder affairs at governmental institutions (Yin, 2018). The Conceptual Framework for CSR and ISR's interaction towards enhanced organizational resilience depicts prioritizing organizational resilience as a focal part of corporate strategy. According to this framework, resilient corporations need to develop CSR and ISR programs in their corporate strategy.

Another facet of the proposed framework is organizational development. Many recent studies show a paradigm shift in the concept of CSR, the fundamental developing role of CSR from Charity to social responsibility, and then to the concept of ISR during the last decade (Shanti \& Saloni, 2016: pp. 36-44). A resilient corporation, especially $\mathrm{MNC}$, implements organizational development plans built on ISR and CSR advocacy principles. In a resilient organization, the phenomenon of ISR has been interwoven into the corporate culture so that employees are voluntarily devoting their efforts to a social movement towards building a sustainable environment. Henceforth, employee engagement in ISR empowers them to construct self-esteem and motivation, leading to employee retention, increased productivity, and profitability of a corporation. Such ISR 
programs promote possibilities of co-creation, creative digital knowledge-sharing platforms in building capacity for meaningful volunteerism (Shanti \& Saloni, 2016: pp. 36-44).

\section{Discussion}

The available literature on ISR, CSR, Culture, and MNCs strategy development have been investigated to help identify theories and ideas that would help express their interplay with the primary focus of creating a conceptual framework facilitating MNC implementation of global CSR initiatives through ISR. Well-orchestrated CSR and ISR coordination is the resilient recipe for any MNCs in the turbulent market. From this perspective, the proposed methodology is a deductive approach in which the existing literature is used to develop a new theoretical or conceptual framework. A scan of existing literature on the subject of our investigation reveals a lack of clarity of the desired interplay of ISR and CSR; therefore, the published publications portray a black box within which the interplay is formalized. This literature review has provided the context and justification for modeling the interworking of complementary elements of CSR and ISR built on the main Social, Economic, and Environment Triple Bottom-Line approach. One could further investigate what is going on inside the interplay framework using secondary data in further steps. Due to the main paradigm shift in social expectations and demands, MNCs encounter increasing global pressure to adapt and constantly improve their CSR programs. The direct consequence of such discoveries enabled inductive reasoning to clearly approach the aims of the research objectives, namely crafting a conceptual model that could be used to better understand the nature of the problem of discrepant CSR initiatives within an MNC that operates across disjoint cultures. It is hoped that this approach not only has resulted in a conceptual framework but also is instrumental in developing a theory. This attempt is a Systematic Analysis of complementary theories that possess the strategic flexibility literature to produce a new conceptual framework. As it is evident in the course of the present literature survey, the integration of these apparently independent concepts leads naturally to an overall conceptual framework.

The search for a remedy to potential conflicting cultural inclinations across national borders in CSR initiatives is what an inductive approach to qualitative analysis is all about. Such inductions involve deriving research-specific concepts such as the unifying effects of ISR in CRS initiatives results in the development of the proposed conceptual framework. The method of Pattern Matching is used that involves predicting a pattern of outcomes based on theoretical propositions to explain what the researchers expect to find from analyzing existing findings (Yin, 2018). This approach underpins the proposed conceptual framework by utilizing current theory and reasoning the proposed framework's adequacy deductively. 
The Conceptual Framework for the interaction of CSR and ISR towards enhanced organizational resilience indicates that CSR and ISR need to be assimilated into a shared, unified, transnational culture. Such an enhancement requires a detailed assessment of CSR to identify corresponding ISR to develop appropriate CSR/ISR strategies. Commitments of all stakeholders are plausible by suitable ISR campaigns in line with key international CSR initiatives. Understanding the reciprocal effects of CSR and ISR in enhancing stakeholder engagement can be studied in further empirical research. Since this paper theoretically proposes a conceptual framework for the interaction of CSR and ISR towards enhanced organizational resilience, it would be beneficial to further research empirically the conceptual framework in an MNC.

\section{About This Research Paper}

Recent attention to Individual Social Responsibility (ISR) as an attempt to meet the demand to fulfill society's demand for more ethical, transparent, and trustworthy organizations is on the rise. These developments have focused on ISR as a fundamental pillar of corporate social responsibility strategy based on ingrained social responsibility and ethical values. The added benefit stemming from ISR-based CSR is the role ISR plays in promoting the sustainability and resilience of the organization.

This study focuses on the enhancement of organizational resilience through positive interaction between ISR and CSR. CSR is the result of evolutionary practices responding to the fulfillment of society's demand for more ethical, transparent, and trustworthy organizations. This paper clearly shows that CSR cannot be effective without adherence to the ISR principles aligned with the demanded premises and values.

\section{Conflicts of Interest}

The authors declare no conflicts of interest regarding the publication of this paper.

\section{References}

Abdelmotaleb, M., Metwally, A., \& Saha, S. K. (2018) Exploring the Impact of Being Perceived as a Socially Responsible Organization on Employee Creativity. Management Decision, 56, 2325-2340. https://doi.org/10.1108/MD-06-2017-0552

Anderson, W. T., \& Cunningham, W. H. (1972). The Socially Conscious Consumer. Journal of Marketing, 36, 23-31. https://doi.org/10.1177/002224297203600305

Sahlin-Andersson, K. (2006). Corporate Social Responsibility: A Trend and a Movement, but for What and of What? Corporate Governance, 6, 595-608. https://doi.org/10.1108/14720700610706081

Antal, A. B., \& Sobczak, A. (2007). Corporate Social Responsibility in France. Business \& Society, 46, 9-32. https://doi.org/10.1177/0007650306293391

Arthaud-Day, M. (2005). Transnational Corporate Responsibility: A Tri-Dimensional 
Approach to International CSR Research. Business Ethics Quarterly, 15, 1-22. https://doi.org/10.5840/beq20051515

Athanasopoulou, A., \& Selsky, J. W. (2015). The Social Context of Corporate Social Responsibility: Enriching Research with Multiple Perspectives and Multiple Levels. Business \& Society, 54, 322-364. https://doi.org/10.1177/0007650312449260

Bãnabou, R., \& Tirole, J. (2010). Individual and Corporate Social Responsibility. Economica, 77, 1-19. https://doi.org/10.1111/j.1468-0335.2009.00843.x

Barakat, S. R., Isabella, G., Boaventura, J. M. G., \& Mazzon, J. A. (2016) The Influence of Corporate Social Responsibility on Employee Satisfaction. Management Decision, 54, 2325-2339. https://doi.org/10.1108/MD-05-2016-0308

Bartel, C. A. (2001). Social Comparisons in Boundary-Spanning Work: Effects of Community Outreach on Members' Organizational. Identity and Identification. Administrative Science Quarterly, 46, 379-413. https://doi.org/10.2307/3094869

Baughn, C., Bodie, N., \& McIntosh, J. (2007). Corporate Social and Environmental Responsibility in Asian Countries and Other Geographical Regions. Corporate Social Responsibility and Environmental Management, 14, 189-205.

https://doi.org/10.1002/csr.160

Baumana, W. C., \& Skitka, J. L. (2012). Corporate Social Responsibility as a Source of Employee Satisfaction. Research in Organizational Behavior, 32, 63-86. https://doi.org/10.1016/j.riob.2012.11.002

Bendoraitienè, E., \& Darškuvienè, V. (2019). CSR Policies and Financial Risks under Stakeholders' Aggressive Actions. In R. Schmidpeter, N. Capaldi, S. Idowu, \& A. Stürenberg Herrera (Eds.), International Dimensions of Sustainable Management (pp. 133-150). Springer. https://doi.org/10.1007/978-3-030-04819-8_9

Bocquet, R., Le Bas, C., Mothe, C., \& Poussing, N. (2017). CSR, Innovation, and Firm Performance in Sluggish Growth Contexts: A Firm-Level Empirical Analysis. Journal of Business Ethics, 146, 241-254. https://doi.org/10.1007/s10551-015-2959-8

Bode, C., Singh, J., \& Rogan, M. (2015) Corporate Social Initiatives and Employee Retention. Organization Science, 26, 1702-1720. https://doi.org/10.1287/orsc.2015.1006

Burton, B., Farh, J.-L., \& Harvey Hegarty, W. (2000). A Cross-Cultural Comparison of Corporate Social Responsibility Orientation: Hong Kong vs. United States Students. Teaching Business Ethics, 4, 151-167. https://doi.org/10.1023/A:1009862130160

Business News Live, Share Market News-Read Latest Finance News, IPO, \& Mutual Funds News (2020, October 10). Digitizing Our Economy with Smart Cities. The Economic Times.

https://economictimes.indiatimes.com/articles/digitizing-our-economy-with-smart-citi es/articleshow/43509680.cms

Carroll, A. B. (2008). Corporate Social Responsibility (CSR) and Corporate Social Performance (CSP). In: R. W. Kolk (Ed.), Encyclopedia of Business Ethics and Society (pp. 1-13). SAGE Publications, Inc. http://sk.sagepub.com.bibl.proxy.hj.se/reference/download/ethics/n206.pdf

Carter, C. R., \& Rogers, D. S. (2008). A Framework of Sustainable Supply Chain Management: Moving toward New Theory. International Journal of Physical Distribution \& Logistics Management, 38, 360-387. https://doi.org/10.1108/09600030810882816

Corbett, C. J., \& Klassen, R. D. (2006). Extending the Horizons: Environmental Excellence as Key to Improving Operations. Manufacturing and Service Operations Management, 8, 5-22. https://doi.org/10.1287/msom.1060.0095 
Dahlsrud, A. (2008). How Corporate Social Responsibility is Defined: An Analysis of 37 Definitions. Corporate Social Responsibility and Environmental Management, 15, 1-13. https://doi.org/10.1002/csr.132

Doh, J. P., \& Guay, T. R. (2006). Corporate Social Responsibility, Public Policy and NGO Activism in Europe and the United States: An Institutional-Stakeholder Perspective. Journal of Management Studies, 43, 47-73. https://doi.org/10.1111/j.1467-6486.2006.00582.x

Eesley, C., \& Lenox, M. J. (2005). Secondary Stakeholder Actions and the Selection of Firm Targets (Working Paper, No. 104). Rock Center for Corporate Governance at Stanford University.

Edwards, V., \& Phan, A. (2014). Managers and Management in Vietnam: 25 Years of Economic Renovation (Doi moi). Routledge.

Freeman, R. (1984). Strategic Management: A Stakeholder Perspective. HarperCollins College Div.

Freeman, R., Harrison, J., Wicks, A., Parmar, B., \& De Colle, S. (2010). Stakeholder Theory: The State of the Art. Cambridge University Press.

https://doi.org/10.1017/CBO9780511815768

Filatotchev, I., \& Stahl, G. K. (2015). Towards Transnational CSR: Corporate Social Responsibility Approaches and Governance Solutions for Multinational Corporations. Organizational Dynamics, 44, 121-129. https://doi.org/10.1016/j.orgdyn.2015.02.006

Gao, C., Zuzul, T., Jones, G., \& Khanna, T. (2017). Overcoming Institutional Voids: A Reputation-Based View of Long-Run Survival. Strategic Management Journal, 38, 2147-2167. https://doi.org/10.1002/smj.2649

Gautier, A., \& Pache, A.-C. (2013). Research on Corporate Philanthropy: A Review and Assessment. Journal of Business Ethics, 126, 343-369.

https://doi.org/10.1007/s10551-013-1969-7

Giacalone, R. A., Paul, K., \& Jurkiewicz, C. L. (2005). A Preliminary Investigation into the Role of Positive Psychology in Consumer Sensitivity to Corporate Social Performance. Journal of Business Ethics, 58, 295-305. https://doi.org/10.1007/s10551-004-5970-z

Gjølberg, M. (2009). The Origin of Corporate Social Responsibility: Global Forces or National Legacies? Socio-Economic Review, 7, 605-637.

https://doi.org/10.1093/ser/mwp017

Ha-Brookshire, J. E., \& Hodges, N. N. (2009). Socially Responsible Consumer Behavior? Clothing and Textiles Research Journal, 27, 179-196. https://doi.org/10.1177/0887302X08327199

Hamel, G., \& Välikangas, L. (2003). The Quest for Resilience. Harvard Business Review, $81,52-63$.

Husain Ebrahim, A., \& Buheji, M. (2020). A Pursuit for a 'Holistic Social Responsibility Strategic Framework' Addressing COVID-19 Pandemic Needs. American Journal of Economics, 10, 293-304. https://doi.org/10.5923/j.economics.20201005.04

Hynes, W. (2019). Organisation for Economic Co-Operation and Development Resilience Strategies and Approaches to Contain Systemic Threats. OECD Conference Centre. https://www.oecd.org/naec/averting-systemic-collapse/SG-NAEC(2019)5_Resilience_st rategies.pdf

Idowu, S. O., \& Leal Filho, W. (2009). Global Practices of Corporate Social Responsibility. Springer. https://doi.org/10.1007/978-3-540-68815-0

Kaplan, R. S., \& Norton, D. P. (2005). The Balanced Scorecard: Measures That Drive Per- 
formance. Harvard Business Review, 83, 172.

Kaz, K. (2019). Building Resilience into the Organization. In R. Schmidpeter, N. Capaldi, S. Idowu, \& A. Stürenberg Herrera (Eds.), International Dimensions of Sustainable Management (pp. 69-85). Springer. https://doi.org/10.1007/978-3-030-04819-8_5

Kleinrichert, D. (2007). Responsibility and Practice in Notions of Corporate Social Responsibility (Order No. 3260072 ABI/INFORM Collection. (304820411). https://www.proquest.com/docview/304820411 ?accountid=34773

Lengnick-Hall, C. A., Beck, T. E., \& Lengnick-Hall, M. L. (2011). Developing a Capacity for Organizational Resilience through Strategic Human Resource Management. $\mathrm{Hu}$ man Resource Management Review, 21, 243-255. https://doi.org/10.1016/j.hrmr.2010.07.001

López Davis, S., Marín Rives, L., \& Ruiz de Maya, S. (2017). Introducing Personal Social Responsibility as a Key Element to Upgrade CSR. Spanish Journal of Marketing-ESIC, 21, 146-163. https://doi.org/10.1016/j.sjme.2017.04.001

Lv, W., Wei, Y., Li, X., \& Lin, L. (2019). What Dimension of CSR Matters to Organizational Resilience? Evidence from China. Sustainability, 11, Article No. 1561. https://doi.org/10.3390/su11061561

Markman, G. M., \& Venzin, M. (2014). Resilience: Lessons from Banks That Have Braved the Economic Crisis and from Those That Have Not. International Business Review, 23, 1096-1107. https://doi.org/10.1016/j.ibusrev.2014.06.013

Matusitz, J., \& Minei, E. (2011). Cultural Adaptation of an MNC in Mexico: A Success Story. Transition Studies Review, 18, 418-429. https://doi.org/10.1007/s11300-011-0200-8

Melé, D. (2009). The Practice of Networking: An Ethical Approach. Journal of Business Ethics, 90, 487-503. https://doi.org/10.1007/s10551-010-0602-2

Mihaela, P. (2018). Individual Social Responsibility: Insights from a Literature Review. Management Research and Practice, 10, 17-26.

Mohr, L. A., Webb, D. J., \& Harris, K. E. (2001). Do Consumers Expect Companies to Be Socially Responsible? The Impact of Corporate Social Responsibility on Buying Behavior. Journal of Consumer Affairs, 35, 45-72. https://doi.org/10.1111/j.1745-6606.2001.tb00102.x

Muller, A. (2006). Global versus Local CSR Strategies. European Management Journal, 24, 189-198. https://doi.org/10.1016/j.emj.2006.03.008

Nasrullah, N. M., \& Rahim, M. M. (2014). CSR in Private Enterprises in Developing Countries. Springer. https://doi.org/10.1007/978-3-319-02350-2

Neely, A., Gregory, M., \& Platts, K. (1995). Performance Measurement System Design: A Literature Review and Research Agenda. International Journal of Operations and Production Management, 15, 80-116. https://doi.org/10.1108/01443579510083622

O’Riordan, L., \& Fairbrass, J. (2014). Managing CSR Stakeholder Engagement: A New Conceptual Framework. Journal of Business Ethics, 125, 121-145. https://doi.org/10.1007/s10551-013-1913-x

Orlitzky, M., Schmidt, F. L., \& Rynes, S. L. (2003). Corporate Social and Financial Performance: A Meta-Analysis. Organization Studies, 24, 403-441. https://doi.org/10.1177/0170840603024003910

Ortiz-de-Mandojana, N., \& Bansal, P. (2016). The Long-Term Benefits of Organizational Resilience through Sustainable Business Practices. Strategy Management Journal, 37, 1615-1631. https://doi.org/10.1002/smj.2410 
Pal, R., Torstensson, H., \& Mattila, H. (2014). Antecedents of Organizational Resilience in Economic Crises-An Empirical Study of Swedish Textile and Clothing SMEs. International Journal of Production Economics, 147, 410-428.

https://doi.org/10.1016/j.ijpe.2013.02.031

Piboolsravut, P. (2004). Sufficiency Economy. ASEAN Economic Bulletin, 21, 127-134.

Porter, M. E., \& Kramer, M. R. (2006). Strategy and Society: The Link between Competitive Advantage and Corporate Social Responsibility. Harvard Business Review, 84, 78-92.

Rest, J. R. (1986). Moral Development: Advances in Research and Theory. Praeger. http://hdl.handle.net/10822/811393

Ryans Jr., J. K., Griffith, D. A., \& White, D. S. (2003). Standardization/Adaptation of International Marketing Strategy; Necessary Conditions for the Advancement of Knowledge. International Marketing Review, 20, 588-603. https://doi.org/10.1108/02651330310505204

Rowley, T. J., \& Moldoveanu, M. (2003). When Will Stakeholders Groups Act? An Interest and Identity Based Model of Stakeholder Group Mobilization. Academy of Management Review, 28, 204-219. https://doi.org/10.5465/amr.2003.9416080

Savitz, A. W. \& Weber, K. (2006). The Triple Bottom Line. Jossey-Bass.

Seville, E. (2018). Building Resilience: How to Have a Positive Impact at the Organizational and Individual Employee Level. Development and Learning in Organizations, 32, 15-18. https://doi.org/10.1108/DLO-09-2017-0076

Shanti, D., \& Saloni, S. (2016). A Paradigm Shift in the Concept of Corporate Social Responsibility to Individual Social Responsibility-The Changing Trends. International Research Journal of Humanities, Engineering \& Pharmaceutical Sciences, 2, 36-44.

Shiu, Y. M., \& Yang, S. L. (2017). Does Engagement in Corporate Social Responsibility Provide Strategic Insurance-Like Effects? Strategic Management Journal, 38, 455-470. https://doi.org/10.1002/smj.2494

Singh, J. (2016). The Influence of CSR and Ethical Self-Identity in Consumer Evaluation of Cobrands. Journal of Business Ethics, 138, 311-326. https://doi.org/10.1007/s10551-015-2594-4

Snider, J., Hill, R. P. \& Martin, D. (2003). Corporate Social Responsibility in the 21st Century: A View from the World's Most Successful Firms. Journal of Business Ethics, 48, 175-187. https://doi.org/10.1023/B:BUSI.0000004606.29523.db

Slack, R. E., Corlett, S., \& Morris, R. (2015). Exploring Employee Engagement with (Corporate) Social Responsibility: A Social Exchange Perspective on Organisational Participation. Journal of Business Ethics, 127, 537-548.

https://doi.org/10.1007/s10551-014-2057-3

Timothy, M. D., Auger, P., \& Eckhardt, G. M. (2010). The Myth of the Ethical Consumer. Cambridge University Press.

Välikangas, L., \& Romme, G. (2013). How to Design for Strategic Resilience: A Case Study in Retailing. Journal of Organization Design, 2, 44-53.

https://doi.org/10.7146/jod.7360

Vitell, S. J. (2015). A Case for Consumer Social Responsibility (CSR): Including a Selected Review of Consumer Ethics/Social Responsibility Research. Journal of Business Ethics, 130, 767-774. https://doi.org/10.1007/s10551-014-2110-2

Vasi, I. B., \& King, B. G. (2012). Social Movements, Risk Perceptions, and Economic Outcomes. American Sociological Review, 77, 573-596. 
https://doi.org/10.1177/0003122412448796

UNIDO (United Nations Industrial Development Organization) (2017). What Is CSR? https://www.unido.org/our-focus/advancing-economic-competitiveness/competitive-tr ade-capacities-and-corporate-responsibility/corporate-social-responsibility-market-int egration/what-csr

Williams, M. E. (2008). Individual Differences and Cross-Cultural Adaptation: A Study of Cultural Intelligence, Psychological Adjustment, and Sociocultural Adjustment. Doctoral Dissertation. TUI University, College of Business Administration.

http://search.proquest.com.bibl.proxy.hj.se/docview/89248636/135EDAE0C81516B1D FE/1 ? accountid=11754

Woo, H., \& Jin, B. (2015). Apparel Firms' Corporate Social Responsibility Communications. Asia Pacific Journal of Marketing and Logistics, 28, 37-55. https://doi.org/10.1108/APJML-07-2015-0115

World Business Council for Sustainable Development. (n.d.). Corporate Social Responsibility: Meeting Changing Expectations. WBCSD Publications.

http://www.wbcsd.org/pages/edocument/edocumentdetails.aspx?id=82\&nosearchconte xtkey=true

Yin, Z. (2018). Test Scenario Generation Using Model Checking. International Journal of Performability Engineering, 14, 1241-1250. https://doi.org/10.23940/ijpe.18.06.p15.12411250

Zadek, S. (2001). The Civil Corporation: The New Economy of Corporate Citizenship. Earthscan.

Zou, P., \& Li, G. F. (2016). How Emerging Market Investors' Value Competitors' Customer Equity: Brand Crisis Spillover in China. Journal of Business Research, 69, 3765-3771. https://doi.org/10.1016/j.jbusres.2015.12.068 